\title{
LA LIBERALIZACIÓN CONTROLADA DEL MERCADO DEL VINO EN NORUEGA (1996-2002): NUEVAS OPORTUNIDADES PARA LA INDUSTRIA VINÍCOLA ESPAÑOLA
}

\author{
José Luis Sánchez Hernández \\ Departamento de Geografía \\ Universidad de Salamanca
}

\section{RESUMEN}

Este trabajo pretende analizar las tendencias del mercado del vino en Noruega tras la formalización del Espacio Económico Europeo en 1994 y valorar la trayectoria de los vinos españoles en este país. Para ello se ha utilizado información recabada sobre el terreno mediante estadísticas oficiales y entrevistas con agentes locales expertos. Durante los últimos años el consumo de vino ha aumentado en Noruega en detrimento de los licores, más tradicionales en sus hábitos gastronómicos. Este proceso se ha acelerado desde 1996, una vez liberalizada la importación de vinos e introducida la competencia por abastecer al Vinmonopolet, empresa estatal que conserva el monopolio de la venta al público y cuyas tiendas no solamente expenden bebidas, sino que funcionan como centros de educación para el consumidor. En este contexto de cambio institucional, el vino español está ganando presencia en Noruega, tanto en el segmento de los vinos de calidad como entre los vinos más corrientes.

Palabras clave: Integración comercial, industria del vino, liberalización, instituciones, monopolio, Noruega.

\section{ABSTRACT}

This article analyses recent trends in the Norwegian wine market after 1994, when the European Economic Space was settled, and assesses the role of Spanish wines in this country. Information and data gathered in Norway, both through interviews with local agents and through official statistics, are used for this purpose. During last years, wine consumption has raised in Norway while spirits fall despite their traditional position in local food patterns. This process has gone faster since 1996, once wine imports were liberalized and strong concurrence to supply Vinmonopolet has appeared. Vinmonopolet is the public corporation that holds the monopoly on retail wine shops, which are not beverage-purchasing facilities only, but also learning places for consumers. In this context of institutional change, Spanish wine is increasing its market share in Norway, both in quality-wine and bulk-wine markets. 
Key words: Trade integration, wine industry, liberalization, institutions, monopoly, Norway.

\section{RÉSUMÉ}

Ce travail cherche à analyser les tendences du marché du vin en Norvège après l'établissement de l'Espace Économique Européen (1994) et aussi à evaluer l'évolution des vins espagnoles dans ce pays. Pour y arriver nous avons utilisé de l'information recherchée sur place, des statistiques officielles et des entretiens avec les experts locaux. Pendant les dernières années la consommation de vin a augmenté en Norvège au détriment des liqueurs, qui étaient plus traditionnels dans leurs habitudes allimentaires. Ce processus s'est accéléré depuis 1996, après la libéralisation de l'importation de vins et l'introduction de la concurrence pour approvisionner le Vinmonopolet, qui est une entreprise de l'Etat qui a encore le monopole de la vente au public et dans les magasins vendent des boissons et jouent aussi le rôle de centres d'éducation pour le consommateur. Dans ce context de changement institutionnel, le vin espagnol devient de plus en plus présent en Norvège tout autant pour les vins de qualité que pour les vins plus courants.

Mots clé: intégration commerciale, industrie du vin, libéralisation, institutions, monopole, Norvège.

Afirmar que el vino está de moda como bebida y negocio no constituye descubrimiento alguno. Basta con observar la proliferación de páginas en Internet, de publicaciones y tiendas especializadas, de encuentros profesionales o de nuevas indicaciones geográficas de calidad, todo ello impulsado por una cuantiosa corriente inversora que, seducida por la cultura del vino, toma posiciones en este dinámico mercado. Ahora bien, esta tendencia tan patente en países productores como España, donde el vino goza de un arraigo secular, se manifiesta de forma muy diferente en países importadores donde su consumo ha estado (o permanece todavía) sujeto a restricciones legales que no son sino la manifestación de convenciones socioculturales que condicionan sobremanera la actitud de sus habitantes y autoridades hacia este producto. Tal es el caso de los países escandinavos, en particular de los más septentrionales: Noruega, Suecia y Finlandia.

Tras su acercamiento institucional a la Europa comunitaria, los países nórdicos se han visto obligados a aligerar o eliminar sus mecanismos de control socioeconómico sobre el negocio del vino para adaptarse a las normas que regulan el comercio internacional y la organización interna de los mercados en los Estados miembros. Esta liberalización comercial tiene implicaciones obvias para países productores como España, ante los que se abren nuevas oportunidades exportadoras si se dedican recursos suficientes a conocer las peculiaridades de estos mercados emergentes (Le Gars y Hinnewinkel, 2000). Es preciso tener en cuenta que su elevado poder adquisitivo, factor siempre propicio para iniciar la penetración comercial, contrasta con unos hábitos de consumo y unos niveles de exigencia muy diferentes a los que rigen en las áreas de venta más tradicionales, por más que la paulatina apertura administrativa y la extendida costumbre escandinava de viajar a países meridionales durante las vacaciones estivales hayan comenzado a impulsar un incipiente cambio de mentalidad.

Este artículo analiza las transformaciones registradas en el mercado del vino en Noruega desde su adhesión al Espacio Económico Europeo (EEE) en 1994, con especial atención a la posición que ocupan los vinos españoles. El estatus jurídico de miembro del EEE obliga a Noruega a acatar buena parte de la normativa comunitaria, pero le confiere cierta 
autonomía en su aplicación interna. Ello convierte a Noruega en un buen ejemplo para el estudio de la influencia de las instituciones y la cultura (definitorias de la identidad territorial colectiva) en el tránsito desde un régimen regulatorio estricto hacia una liberalización parcial que antepone la protección, quizá paternalista, del ciudadano-consumidor frente a las temidas consecuencias de la aplicación mecánica de las leyes de la oferta y la demanda. Solamente desde esta perspectiva institucional, que viene suscitando un notable interés en la Geografía Económica más actual (Salom, 2003; Sánchez, 2003), cabe comprender la pervivencia del monopolio estatal para la venta minorista de bebidas alcohólicas y los elevados gravámenes fiscales aplicados a estos productos.

Esta investigación se fundamenta en información recogida en Oslo y la región de Bergen $^{1}$ durante sucesivas estancias de trabajo iniciadas en 1999. A los datos estadísticos sobre consumos, ventas, precios o impuestos publicados por organismos oficiales hay que añadir la información recabada mediante entrevistas semiestructuradas con directivos y empleados del monopolio estatal (Vinmonopolet), con importadores y con distribuidores particulares, todos ellos expertos conocedores de los cambios suscitados en el mercado tras la entrada en vigor de las nuevas disposiciones legales en enero de 1996.

El artículo se estructura en cinco apartados: la presentación de los cambios en la organización y regulación del mercado, la exposición de las tendencias más recientes en el terreno del consumo y el análisis del papel de los vinos españoles en todo este entramado ocupan el núcleo del trabajo, que se cierra con unas conclusiones. Todo ello viene precedido por una breve reflexión sobre el impacto de la apertura de los mercados (otra modalidad más de la tan traída y llevada globalización) en dos campos concretos: los retos y expectativas planteados a los sectores industriales más tradicionales o maduros, caso de la producción alimentaria, y las exigencias de transformación institucional en los territorios que se incorporan a la escena económica internacional.

\section{La integración comercial en el contexto de la globalización: una aproximación geográfica}

El estudio del proceso de globalización económica puede abordarse desde diferentes puntos de vista. La interdependencia y preponderancia de los mercados financieros, la constitución de empresas-red y de redes de empresas que organizan cadenas multinacionales de producción, la cuantía, composición y dirección de los flujos de mercancías, la caracterización de los agentes impulsores de la internacionalización, sus desiguales consecuencias sociales, laborales y ambientales, la exigencia de nuevas respuestas desde la esfera regulatoria y las diversas modalidades de inserción (o exclusión) de los territorios en la nueva división espacial del trabajo son algunas de las vías más habituales de aproximación al análisis de una realidad poderosa e ineludible, pero que aún dista de determinar por completo todas las claves que gobiernan la trayectoria social y económica de países, regiones y ciudades.

1 Este artículo se encuadra en los proyectos de investigación «Desarrollo territorial y procesos de innovación socioeconómica en las comarcas vinícolas de Castilla y León» (Ministerio de Ciencia y Tecnología, 2004-2006, ref. BSO-2003-07603-C08-05) y «La contribución del sector vitivinícola al desarrollo rural en Castilla y León» (Junta de Castilla y León, 2004-2006). También debo agradecer al Vicerrectorado de Investigación de la Universidad de Salamanca la concesión de una bolsa de viaje dentro del programa de movilidad del personal investigador, así como la ayuda recibida en el Institutt for Geografi de la Universidad de Bergen, muy en especial por parte del Dr. Knut B. Lindkvist. 
Siendo la globalización un proceso espacial que pone de relieve las diferentes capacidades de los territorios para enfrentarse a los retos de un capitalismo que amplía permanentemente su ámbito de reproducción (Méndez, 1997; Amin, 1999; Palazuelos y Vara — coords.—, 2002), la Geografía Económica puede contribuir a su conocimiento si permanece fiel a sus señas de identidad y dirige sus esfuerzos hacia aportaciones integradoras en las que el territorio aparezca como referente central de la reflexión. Frente a las descripciones impresionistas apoyadas en las manifestaciones más espectaculares (volumen de transacciones en los mercados de divisas, fusiones y adquisiciones entre empresas multinacionales, posibilidades operativas asociadas al uso de las tecnologías de la información y la comunicación), el enfoque geográfico debe proponer argumentaciones relacionales (Bathelt y Glückler, 2003) que desvelen las múltiples interdependencias que vinculan entre sí a los variados procesos y territorios implicados. Esta labor puede acometerse en diferentes escalas, desde la mundial a la local, con la vista siempre puesta en las modalidades de participación de los territorios en la globalización, en su habilidad para aprovechar las oportunidades que se presentan con la apertura de los mercados y en sus estrategias de reacción ante la llegada del capital exterior, la liberalización de los intercambios o la mutación en los valores y principios que, durante décadas, han orientado el comportamiento de los grupos humanos y los individuos que los integran.

Dada la consistencia que todavía se reconoce al Estado-nación como filtro modulador del proceso de globalización (Martínez, 2000; Dicken, 2003), un estudio a escala nacional permite aplicar este enfoque geográfico a la valoración de la particular respuesta de los agentes públicos y privados ante una de las modalidades clásicas del proceso de internacionalización (Buesa y Molero, 1998; Lobejón, 2001): la liberalización de los intercambios comerciales derivada de la participación en bloques económicos regionales. La incorporación de nuevos países a estos bloques representa una modalidad extensiva de ampliación del espacio de las transacciones mercantiles que genera, al menos, dos efectos estrechamente vinculados: abre nuevas perspectivas de negocio a los productores extranjeros y reclama modificaciones de diverso calado en la organización y regulación de los nuevos mercados. Ambos son susceptibles de una interpretación geográfica.

En el primer caso, las áreas especializadas en sectores industriales maduros, caso de numerosas regiones españolas, pueden resultar particularmente beneficiadas. Conforme a la teoría del ciclo del producto, la diversificación territorial de las ventas en dirección hacia mercados con cierto poder adquisitivo y donde el producto resulta exótico o novedoso constituye una fórmula eficaz para retrasar el envejecimiento de los productos, problema habitual en los mercados domésticos saturados por una oferta en continua renovación y por una fuerte presión competitiva derivada de la concurrencia de numerosos productores. Estos sectores se organizan con frecuencia en forma de sistemas territoriales de empresas que, como reconocen desde hace ya tiempo geógrafos y economistas (Porter, 1991; Malmberg, 1996; Markusen, 1996; Krugman, 1997; Maskell y otros, 1998; Alonso y Méndez — coords. - 2000; Antonelli y Ferrão — coords.— 2001; Gilly y Torre — dirs.— 2001; Dupuy y Burmeister - dirs. - 2003) encuentran en la proximidad geográfica y la identificación con el territorio uno de los factores cruciales de su competitividad. La incorporación de nuevos mercados al espacio de los intercambios puede inducir efectos muy positivos en los distritos industriales más activos en el aprovechamiento de estas oportunidades, bien a través de la diferenciación del producto o de la oferta de precios muy ajustados, según el tipo de cliente al que se pretenda acceder.

En segundo lugar, los países que se adhieren a un bloque comercial regional se ven obligados a adecuar su legislación a las exigencias de la entidad supranacional que, por lo común, reclama a su nuevo miembro mayores facilidades para la circulación de mercancías 
y capitales. Ello implica una mayor competencia dentro del mercado doméstico para los productores nacionales que gozaban de cierta protección antes de la adhesión, así como una mayor presencia de nuevas mercancías ajenas al perfil de especialización de la industria local. Cuando las exigencias de liberalización afectan a un monopolio estatal, el impacto sobre la vida del país es mayor a causa de la introducción de mecanismos de mercado donde antes primaba el interés público y de la aparición de nuevos agentes comerciales que buscan consolidar sus posiciones con rapidez. Sobre todo en mercados dirigidos al consumidor final, la publicidad juega un papel importante en la difusión de los nuevos productos $\mathrm{y}$, merced a la imagen asociada a las grandes marcas corporativas, contribuye a la progresiva configuración de un patrón de consumo cada vez más homogéneo, al menos en el mundo desarrollado.

Tal modificación del marco de relaciones afecta forzosamente a las antiguas convenciones que vehiculan los comportamientos colectivos. La cuestión consiste en averiguar si el territorio, entendido como producto de la identificación de la sociedad con su marco geográfico de relaciones y convivencia, es capaz de integrar con armonía los imperativos exógenos con su propia regulación heredada, fruto a su vez de un denso tejido de pactos implícitos y compromisos colectivos o, por el contrario, opta por la desintegración de su entramado de instituciones y organizaciones para amoldarse a los modelos importados, con el riesgo de perder algunos de los elementos que definen su identidad común y su cohesión social.

\section{La regulación del mercado del vino en Noruega: del monopolio estatal a la libera- lización controlada}

Hasta el mes de diciembre de 1995 estuvo vigente en Noruega el régimen de monopolio estatal absoluto sobre la importación y venta de bebidas alcohólicas. El Vinmonopolet data de 1922 y representa un intento de solución duradera al problema de la gestión social del consumo de alcohol. Como en otros países septentrionales (Corbin y Perrot, 1993), el alcoholismo, descrito y denunciado como enfermedad en 1849 por el médico sueco Magnus Huss (Orfali, 1993), azotó durante el siglo XIX a una parte importante de la población campesina del país, que parecía encontrar en los licores fuertes (como el licor de patata, la bebida nacional) una forma de evasión ante el intenso frío, la lluvia pertinaz, las largas noches invernales, la desarticulación de las comunidades rurales provocada por la cuantiosa emigración a América y el consiguiente aislamiento en las granjas dispersas por un territorio cuyo accidentado relieve entorpece aún hoy los desplazamientos. La magnitud del problema llevó a las autoridades a convocar un referéndum en 1919, que aprobó la prohibición de la venta y consumo de todo tipo de bebidas alcohólicas. En esta decisión no estuvieron ausentes las influencias religiosas, dada la confesionalidad luterana del Estado noruego y el radicalismo de determinados grupos que se han distinguido siempre por su completo rechazo al consumo de bebidas alcohólicas, considerándolas un grave peligro para la sociedad.

Este cierre del mercado levantó fuertes protestas de Francia, que amenazó con represalias comerciales y consiguió que el gobierno noruego admitiera la importación de vino, cuya disponibilidad en todo el territorio nacional debía ser asegurada por el Vinmonopolet, constituido como compañía privada bajo control público y obligado a velar por los principios del consumo moderado. En 1923 su monopolio se extendió a los vinos generosos, en 1926 a los licores, y en 1939 la empresa pasó definitivamente a la propiedad estatal, con el mandato expreso de eliminar el afán de lucro en este mercado y de contribuir a la limitación del consumo de alcohol por razones sociales y sanitarias. 
El monopolio consistía hasta 1996 en el ejercicio en exclusiva del derecho de importación y venta de bebidas alcohólicas; solamente las cervezas con menos de 4,75 grados se venden sin trabas en tiendas de alimentación. Desde su sede central de Oslo, el Vinmonopolet gestiona una extensa cadena de tiendas minoristas (192 en diciembre de 2003) que ofrecen al público mayor de edad una amplísima gama de vinos y licores. Ello exigía la organización de una vasta red logística (Arcus Distribusjon) dedicada al abastecimiento permanente de un complejo comercial que se subdivide en cuatro sub-regiones: Este y Sur (controlados desde Oslo), Oeste (desde Bergen) y Norte (desde Trondheim). Siguiendo un claro esquema de integración vertical orientado a la rentabilización del sistema de distribución, la filial Arcus Produkter cubría el segmento de caldos baratos envasando con marcas propias el vino adquirido a granel en el extranjero, además de elaborar algunos licores.

La constitución del Espacio Económico Europeo en enero de 1994 obligó a las autoridades noruegas a modificar algunos de los principios reguladores del sistema por el lado de la oferta, mientras permanecen otros de índole sociocultural relacionados con la gestión de la demanda. Se perfila así un modelo mixto, un híbrido entre intervención y liberalización que define la identidad actual del mercado noruego de vino y licores como el resultado de una inserción controlada en los nuevos esquemas comerciales supranacionales que no sacrifica los valores colectivos a los postulados del librecambio indiscriminado.

\subsection{Hacia una apertura limitada de la oferta}

La incorporación de la normativa comunitaria se ha dejado sentir sobre todo en los mecanismos de abastecimiento. Desde enero de 1996, el Vinmonopolet tan sólo retiene el control exclusivo sobre su red de tiendas, únicos puntos de venta minorista de vino y licores. La liberalización de la importación y de la distribución y venta a hoteles, restaurantes y empresas de catering (el llamado mercado HORECA) fomenta la aparición de nuevos actores privados con distinto grado de especialización: existe hoy un centenar de agentes comerciales dedicados a la importación, junto a unos noventa mayoristas que trabajan para clientes locales y regionales. También ha surgido tres operadores logísticos integrales que, además de importar y vender, prestan servicios de transporte y distribución a mayoristas e importadores. La presión de estos agentes privados obligó al Vinmonopolet a desprenderse de Arcus para evitar que su posición dominante hiciera inviable la consolidación de nuevos agentes. Arcus Produkter sigue envasando vinos importados y destilando licores, mientras Vectura (nuevo nombre de Arcus Distribusjon) ejerce como operador integral en competencia con los privados y, además, debe atender las necesidades logísticas de la red comercial del Vinmonopolet; su cuota de mercado declarada (www.vectura.no) es del $57 \%$ del negocio de distribución mayorista y presta servicios a cincuenta importadores de bebidas alcohólicas.

Esta nueva estructura es responsable de la introducción de la competencia entre los agentes privados por surtir al Vinmonopolet (82\% del mercado total) y a los clientes HORECA (18\% restante, con datos de 2002). Las consecuencias no se han hecho esperar en el segmento HORECA, hoy en manos de los nuevos importadores y mayoristas particulares gracias a su rapidez en las entregas, a la constante incorporación de novedades a sus catálogos y al asesoramiento puntual a los clientes sobre las características de los productos. Vectura ha sido desplazada de este segmento más competitivo por su falta de agilidad en el servicio a una clientela que busca vinos de buena calidad y variada procedencia geográfica, sin que el precio sea el determinante principal de sus pedidos.

Una particularidad convierte al mercado HORECA en punta de lanza de la evolución del sistema. La publicidad de todo tipo de bebidas alcohólicas continúa rigurosamente 
prohibida en Noruega. Registrada desde hace tiempo, la dirección web del monopolio (www.vinmonopolet.no) sólo ha comenzado a ofrecer contenidos y servicios desde el año 2003, y en las páginas de los agentes privados se requiere un código de acceso, restringido a clientes y proveedores. En estas condiciones, la introducción de nuevas marcas y productos es muy complicada, quedando la restauración como único canal directo para el lanzamiento de novedades ante el público. En ausencia de uno de los ingredientes clave de la competencia marquista, los vínculos de confianza entre los importadores y restauradores más innovadores resultan decisivos para la introducción de nuevas elaboraciones y áreas productoras en Noruega, del mismo modo que los primeros se sirven de los resultados de los segundos para evaluar las posibilidades de éxito de cualquier novedad antes de abordar su adquisición a mayor escala.

Una parte del mercado noruego de bebidas alcohólicas comienza así a operar bajo los patrones habituales en la Unión Europea. Pero el segmento minorista dista todavía de funcionar según los principios del libre mercado toda vez que el Vinmonopolet se arroga el doble papel de intérprete de las demandas de los consumidores y atemperador de la capacidad de influencia de los abastecedores, evitando que unos y otros entren en contacto directo. En efecto, una vez privado de su cometido importador, el monopolio se surte ahora de los proveedores particulares, que orientan su labor comercial en función del plan anual de compras que publica el Vinmonopolet a tal efecto. Este documento determina la oferta real a disposición del público, en la que la capacidad de influencia de los proveedores es limitada y, en todo caso, fructifica con lentitud.

El Vinmonopolet ofrece un catálogo de 5.500 bebidas diferentes (vinos en su inmensa mayoría), pero los establecimientos mayores (con ventas superiores al millón de litros anuales), disponen de un máximo de 2.000 referencias, y el establecimiento-tipo ofrece en torno a 800 productos, lo que cubre las peticiones de un $95 \%$ de los usuarios. En la práctica, se ofrecen al cliente cinco listas diferentes de productos. La lista básica está integrada por los más demandados, divididos en segmentos y que, para permanecer en ella, deben lograr un volumen mínimo de ventas que justifique el flujo logístico preciso para mantener abastecida toda la red comercial. La lista de lote único contiene productos que se venden por partidas, no por botellas. La lista de los proveedores incluye vinos no disponibles en el stock del monopolio, pero que pueden pedirse a los proveedores por encargo del cliente. La lista de prueba es un resquicio abierto a la innovación: incluye productos que la dirección cree oportuno introducir en el mercado y que se someten al juicio del cliente en 20 tiendas. Solamente aquellos que logren un $1 \%$ de las ventas de su segmento en los primeros seis meses de permanencia serán incorporados a la oferta básica. Desde 1996 se ha introducido un estímulo a la competencia entre las tiendas con la llamada lista local, confeccionada por el responsable de cada establecimiento con productos de mayor calidad o mejor aceptación en su área de ventas; con todo, sólo los clientes de las trece ciudades que cuentan con más de una tienda pueden beneficiarse de esta oportunidad.

Todas estas listas figuran en catálogos de renovación bimestral que los clientes pueden retirar gratuitamente en las tiendas, así como en la web de la empresa. Se trata de catálogos de gran calidad, editados en color y con una detallada información sobre cada marca de vino: país y región de procedencia, bodega embotelladora, variedades de uva, añada, volumen y tipo de envase, nota de cata, características organolépticas, precio y alimentos más adecuados para su acompañamiento. A esta información comercial se añaden la edición regular de folletos y revistas gratuitas sobre el mundo del vino y la labor de asesoría de los empleados, que reciben una completa formación previa a fin de aconsejar a los clientes más indecisos o inquietos sobre las características de los vinos y los mejores maridajes con las diferentes clases de alimentos. 
Entre la lista local y la básica, las mejores tiendas llegan a ofrecer unas 1.500 referencias in situ a sus clientes. Ello plantea costosos retos logísticos a Vectura, que no sólo debe mantener la red abastecida respetando los precios que figuran en catálogo. En efecto, una única botella de la lista de los proveedores solicitada en Honningsvåg, a 2.000 kilómetros de Oslo, debe servirse sin recargo alguno por los portes, a fin de garantizar la igualdad de todos los ciudadanos ante lo que no deja de ser un servicio público. Siguiendo el mismo principio, los pedidos realizados por teléfono desde localidades carentes de tienda del monopolio no implican coste suplementario alguno para el cliente.

\subsection{La pervivencia de las prácticas de contención de la demanda}

Pero los cuidados catálogos y la amplia oferta, que incluye vinos de una treintena de países, no pretenden estimular el consumo de bebidas alcohólicas. Más bien, tan esmerado sistema de información al público debe entenderse como una pieza más de la estrategia oficial de moderación de la demanda, anclada en la convicción de que el alcohol es un peligro superfluo y no un producto que fomente el bienestar individual o colectivo. En este terreno, la respuesta noruega (local) a la corriente liberalizadora europea (global) ha sido firme, primando el compromiso con los principios heredados frente a la aceptación de reglas de juego ajenas.

La imposición sobre el alcohol se mantiene en niveles muy elevados. Un vino tinto de la calidad más elemental servido por el distribuidor a 16 coronas por litro (2,28 euros) cuesta en el Vinmonopolet cerca de 68 coronas (9,70 euros), que incluyen cuatro impuestos (sobre los productos alimenticios, sobre el alcohol, sobre los envases no reciclables y sobre el valor añadido) y dos tasas (una para sufragar la recuperación de las botellas reciclables y otra para compensar al Estado los costes derivados del control sobre el mercado del alcohol) por un valor total de 43 coronas, más los beneficios del monopolio ( 8 coronas, que se desglosan en un fijo de 3,5 coronas por envase y un $28 \%$ del precio base). Tan pesadas cargas fiscales sirven para establecer un precio mínimo muy elevado de acceso al alcohol que hace imposible comprar una botella de vino por menos de 70 coronas (10 euros), precio aproximado de los caldos de peor calidad ${ }^{2}$. Ello constituye un factor de disuasión evidente para el comprador y justifica la imagen de producto caro de consumo ocasional, ligado a acontecimientos especiales, que acompaña al vino en Noruega, donde regalarlo constituye todavía signo de distinción y halago. A la vez, se asegura así la primacía comercial del Vinmonopolet, pues el mercado HORECA debe aplicar sus propios márgenes de beneficio sobre los precios de referencia, resultando unos precios finales tan disuasorios que limitan el crecimiento del consumo no doméstico.

Desde los esquemas mediterráneos, adquirir vino en Noruega no sólo resulta caro por su precio, sino también algo complicado por las especiales características de las tiendas del monopolio. En la mayor parte de los casos, los productos no se encuentran al alcance del público, sino que deben ser pedidos en el mostrador a los empleados, quienes los retiran del almacén. Solamente las novedades se exponen en unas escuetas vitrinas. Este sistema pretende evitar la compra impulsiva introduciendo cierto lapso de tiempo entre la entrada en la tienda y la recepción del pedido, ya que lo común es tener que guardar cola antes de ser atendido. Por supuesto, no se expenden bebidas alcohólicas a menores de edad y las

2 El producto más vendido por el monopolio en 2002 fue Gato Negro Cabernet Sauvignon (1,5 millones de litros), un vino chileno que se ofrece en botellas de 37,5, de 75 y de $300 \mathrm{cl}$ a 46, 77 y 293 coronas, respectivamente. 
tiendas cierran los sábados por la tarde y todo el domingo. Y en los mismos anaqueles donde se apilan los diferentes catálogos, los clientes pueden encontrar también folletos muy detallados que orientan a los padres en la prevención del alcoholismo en la familia o alertan de los riesgos que implica el alcohol en caso de embarazo, de tratamiento farmacológico o de consumo inmoderado. Pese a estas condiciones, los clientes del monopolio prefieren acudir a las tiendas, donde pueden recibir información interesante, en vez de recurrir al servicio a domicilio: la venta directa suponía el 89\% del total en 1994 para alcanzar el $95 \%$ en 1998, mientras la entrega a domicilio permanece estancada en el $2 \%$ desde 1996.

Ello explica el sostenido proceso de apertura de nuevas tiendas, habida cuenta de que en 1996 el monopolio sólo disponía de 113 establecimientos. Esta expansión está supervisada por el Ministerio de Salud y Asuntos Sociales y se rige por criterios de servicio público, ya que en la actualidad el $83 \%$ de la población noruega dispone de una tienda del monopolio en su municipio de residencia y sólo el cinco por ciento vive a más de $50 \mathrm{~km}$ del establecimiento más próximo. Para reducir los inconvenientes que padecen los habitantes de las áreas rurales más remotas y de poblamiento más disperso, se está estudiando la implantación de los llamados Minipol, pequeñas tiendas que se ubicarán siempre en lugares distantes al menos $30 \mathrm{~km}$ de un establecimiento completo y cuyo surtido estará integrado por las cien marcas de bebidas más populares.

FIgURA 1: Plano de un establecimiento-tipo del Vinmonopolet

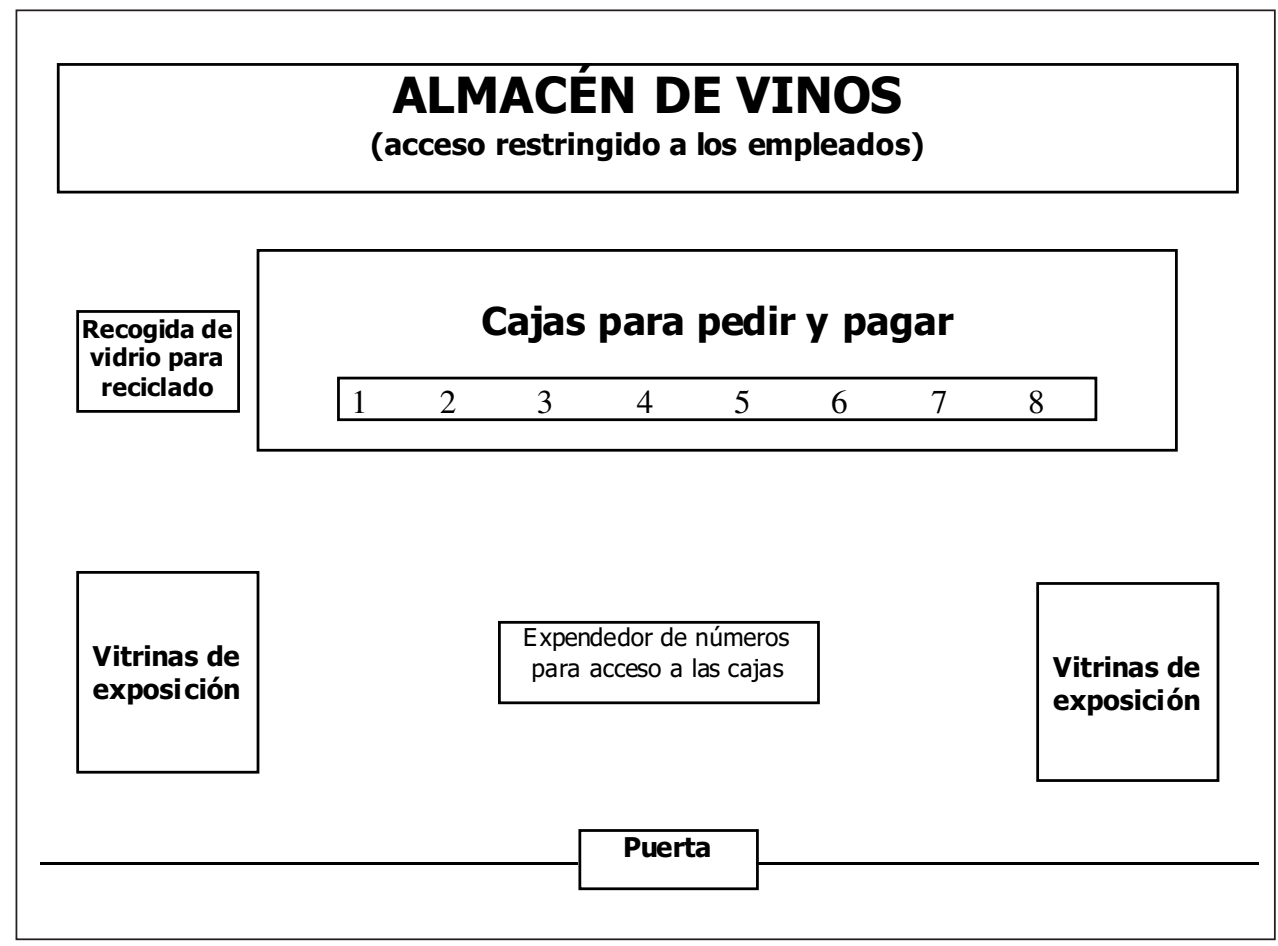

Fuente: Trabajo de campo. Elaboración propia. 
El rígido formato minorista tradicional ha sufrido algunas transformaciones desde finales de 1999 con la apertura de tiendas-autoservicio, es decir, con acceso directo del cliente a las botellas y posterior abono del precio en las cajas. Se busca así diversificar las referencias vendidas, facilitar la penetración de nuevos productos y acomodar los establecimientos a los tiempos, a sabiendas de que exige un esfuerzo adicional de formación técnica para los dependientes, que deberán contestar preguntas sobre mayor número de bebidas. El proyecto, supervisado por el Instituto Nacional para la Investigación sobre el Alcohol y las Drogas, prevé que, en caso de que las ventas se incrementen en exceso, la nueva fórmula comercial se cancelará, en una clara manifestación de la voluntad política de mantener el statu quo del mercado.

Así, hasta 2001 sólo se habían abierto o transformado en autoservicio 21 establecimientos, pero en 2002 la cifra se ha elevado rápidamente hasta los 71, habida cuenta del moderado crecimiento en el volumen vendido (7,7\% en 2000 y $2 \%$ en 2001). En 2002 se ha pasado al 8,7\%, la cifra más alta desde 1996, pero el Vinmonopolet lo atribuye más bien a la reducción de los impuestos sobre los licores, aprobada por el Parlamento para combatir su producción y consumo ilegal, práctica aún vigente y que ha provocado algunos fallecimientos por intoxicación derivada de la ingestión de bebidas mal destiladas. La apertura de nuevas tiendas también se justifica por este motivo, tras haberse demostrado científicamente en algunas regiones noruegas que una oferta controlada, pero legal, de alcohol no ha supuesto un incremento sustancial del consumo total, sino un desplazamiento del mismo desde los cauces marginales a los oficiales.

Así pues, las tiendas del Vinmonopolet, principal lugar de encuentro entre oferta y demanda, desempeñan con igual rigor la doble función de punto de venta y centro de formación del consumidor, conforme al principio de que una buena educación es la mejor prevención contra el abuso. De hecho, la empresa no busca el crecimiento sostenido de las ventas, prohibido por ley hasta el punto de que no se proporciona formación en técnicas de venta a los dependientes. La conciencia de servicio público eficaz subyace a la vez en el surtido catálogo disponible, en la amplia información que se presta al cliente interesado y en un despliegue de medios más o menos sutiles para moderar el consumo. A juicio de los noruegos, la vigencia del monopolio expresa el consenso colectivo sobre la conveniencia de restringir el acceso al alcohol por solidaridad con las personas incapaces de practicar un consumo responsable, de forma que la regulación sólo incorporará las innovaciones que no pongan en peligro ese acuerdo explícito.

\section{Las tendencias recientes del mercado del vino en Noruega}

Dada su posición dominante, las completas estadísticas que ofrece el Vinmonopolet en sus informes anuales proporcionan una imagen precisa sobre las tendencias más recientes en el consumo de bebidas alcohólicas en Noruega. Las ventas han aumentado de 39,4 a 58,7 millones de litros entre 1989 y 2002, lo que representa un salto desde 5.599 hasta 9.068 millones de coronas corrientes. Su distribución muestra una importancia creciente del vino fresco o tranquilo (por debajo de los 15 grados) en detrimento de los destilados de mayor graduación, mientras productos como los vinos generosos y de aperitivo, las cervezas especiales y los licores y vinos bajos en alcohol mantienen su participación más o menos estable, aunque su posición dentro de la estructura de ventas es muy débil, por debajo del 5\%. Si en 1989 el vino representaba el 64,5\% del volumen vendido por el monopolio frente al 28,3\% de los licores, las cifras de 2002 sitúan al vino en el 77,6\%, muy por delante del $19 \%$ correspondiente a estos últimos. 
Estos datos tienen su correlato en los promedios de gasto y consumo alcohólico total. El predominio de la cerveza es indiscutible, tanto por razones de accesibilidad como de precio: desde 1989 recibe el 55\% del gasto por habitante y año en bebidas alcohólicas, lo que se traduce en unos 63 litros anuales. Vino y licores se disputan la otra mitad del mercado con suerte dispar. El vino gana presencia en la estructura de gasto (del 20,9\% al $25,2 \%$ ) y en el consumo por habitante (de 8,1 a 13,5 litros/año), mientras los licores retroceden del $25,1 \%$ al $20,7 \%$ del gasto y de 3,3 a 2,5 litros. Y en términos relativos, el vino pasa del $10,8 \%$ al $16,9 \%$ del volumen consumido, arrebatando cuota a los licores (del $4,3 \%$ al $3,2 \%$ ) y a la cerveza (del $84,9 \%$ al $79,9 \%$ ). Así pues, el vino exhibe un fuerte dinamismo entre 1989 y 2002, con aumentos del $65 \%$ en consumo total y del $60 \%$ en gasto anual por habitante.

La evolución anual de estos indicadores revela que esta progresión del vino se acelera a partir de 1996. Entre 1989 y 1995 el volumen de vino vendido creció en 4 millones de litros y el consumo anual per capita en 0,65 litros. En los seis años de apertura (1996-2002) se venden 16,7 millones de litros más y el consumo por habitante crece 4 litros, mientras la cerveza se estanca en ambas magnitudes. Por lo tanto, la nueva regulación del mercado parece contribuir al crecimiento del consumo de vino, proceso que, al menos en parte, podría explicarse por la contención de los precios derivada de la competencia entre los proveedores del Vinmonopolet, de las economías de escala que genera su tamaño y de la ausencia de afán de lucro: a falta de otros datos, se puede decir que en 2002 el precio medio del litro de bebida alcohólica era de 154 coronas, el mismo que en 1996 e incluso menor que en 1999 (162 coronas).

Comprobada la mayor presencia del vino en los hábitos alimentarios noruegos, interesa ahora averiguar qué variedades atraen más al consumidor. Como ha ocurrido en otros países occidentales, los vinos generosos (jerez, oporto, montilla...) han perdido cuota, desde los 2,3 millones de litros vendidos en 1989 (6\% del total) hasta los 1,2 millones de 1998 (2\%), lastrados por los altos impuestos sobre las bebidas con más de quince grados.

Son los vinos tranquilos los protagonistas de esta expansión cuantitativa, acompañada por cambios cualitativos importantes. Las compras se decantan con nitidez hacia el vino tinto, que en 1994 representaba el 58,6\% del volumen de vino vendido y en 2002 alcanzaba ya el $71,1 \%$ (32,4 millones de litros). Solamente el blanco parece capaz de resistir tal empuje, pues sus ventas pasan de 8,6 a 10,3 millones de litros, aunque su cuota desciende del $31 \%$ al $22 \%$. Rosados, espumosos y otros vinos ocupan una posición marginal y retroceden desde el 10,5\% hasta el 6,3\%. De nuevo la apertura regulatoria parece impulsar esta transformación, pues entre 1996 y 2002 las ventas de tinto crecen en 13,5 millones de litros, cuando entre 1994 y 1996 sólo aumentaron 2,6 millones.

Esta preponderancia creciente del tinto constituye una señal de confluencia con los gustos mediterráneos, toda vez que los países escandinavos han sido tradicionalmente propicios para el vino blanco, como reconoce el propio Vinmonopolet ${ }^{3}$. El efecto favorable de la contención de precios en los vinos de crianza y reserva, que se tornan más asequibles, puede explicar este desplazamiento. Otro factor que debe tenerse en cuenta es el hábito de viajar a países mediterráneos durante las vacaciones. En estas estancias resulta habitual el consumo de vinos tintos, más populares, más variados y también mucho más baratos en estas áreas productoras, de forma que los turistas noruegos regresan a su país con nuevas experiencias que después se reflejan en sus exigencias en las tiendas del Vinmonopolet. La

3 Mientras en Noruega las ventas de vino tinto triplican a las de blanco, en Suecia la proporción es de tres a dos y en el Reino Unido de uno a uno. 
moda del vino que viven los países meridionales influye, pues, más allá de sus fronteras orientando el consumo hacia una progresiva homogeneización y aprovechando el turismo para la promoción indirecta de nuevos vinos y zonas productoras.

La distribución temporal del consumo todavía presenta una fuerte concentración en la tarde del sábado, con cenas donde se mezclan vinos diferentes (en tipo y calidad), prolongadas con veladas en las que no faltan los licores. El resto de la semana apenas se consumen bebidas alcohólicas. Los datos de intensidad horaria de compra que proporciona el Vinmonopolet así lo atestiguan: de lunes a jueves no se rebasan los diez clientes por caja y hora y las frecuencias superiores a veinte clientes sólo se alcanzan el viernes por la tarde (de 14 a 17 horas) y la mañana del sábado (de 12 a 15 horas). Durante estos dos días, además, las tiendas abren una hora antes y el viernes cierran una hora después del horario habitual (de 10 a 17 horas).

Ahora bien, el tradicional consumo sabatino, un tanto compulsivo, comienza a ceder paso ante un reparto más equilibrado durante la semana, conforme se va difundiendo una incipiente cultura del vino. Poco a poco, el consumidor noruego prefiere disfrutar un vino de calidad y no limitarse a ingerir una bebida que anime la vida social. Prueba de ello es la caída de las ventas de vinos adquiridos a granel en zonas productoras y envasados por Arcus: en 1989 esta empresa acaparaba con tales productos el 60\% del segmento, porcentaje que en la actualidad no rebasa el $25 \%$. También se está registrando un tenue aumento del consumo de vinos más caros. En 1995 las botellas más vendidas costaban unas 60-70 coronas y solamente un 3\% correspondía a botellas de 100 ó más coronas. Los datos más recientes, de 1998, indican que el precio-tipo se situaba ya en torno a las 80 coronas, con un $35 \%$ de las ventas entre 71 y 80 coronas, un $24 \%$ entre 81 y 100 y un significativo $8 \%$ por encima de las 100 coronas.

Las decisiones de compra comienzan a tener en cuenta argumentos diferentes del precio, aunque éste todavía las determine en buena medida. Para el consumo más frecuente o para el uso en casas de campo, el bag-in-box de 3 ó 5 litros goza de gran aceptación porque conjuga buen precio, calidad aceptable para los estándares locales y gran facilidad de transporte y conservación en un país de poblamiento tan disperso ${ }^{4}$. La diferencia estriba en que este envase ya no contiene, como era tradicional, graneles envasados en Noruega, sino vinos envasados en origen para satisfacer esta clase de demanda, común a otros países nórdicos. Para las ocasiones más especiales, sin embargo, se prefiere la compra de vinos con algún tipo de indicación geográfica de origen, muy valorada por la escasa prensa local especializada. Como en toda Europa, la identificación del vino con un lugar concreto parece mejor argumento competitivo que la simple mención de la variedad de uva, esgrimida desde California y los nuevos productores del hemisferio sur, como se verá en el siguiente apartado.

Ahora bien, este hecho no está reñido con la fidelidad hacia determinadas marcas consideradas emblemáticas de cada demarcación (caso de Marqués de Cáceres en Rioja o Torres en el Penedés) como consecuencia de su esfuerzo individual de penetración comercial. Como apuntan los responsables del Vinmonopolet, es frecuente que los clien-

4 El bag-in-box compite con éxito frente a la tradicional elaboración doméstica de un sucedáneo de vino a base de agua y extracto concentrado de uva que se somete a un proceso de fermentación natural en cubas de plástico de 25 litros. El extracto puede adquirirse en tiendas especializadas de libre apertura pero que también tienen prohibida toda publicidad. En todo el Oeste de Noruega solamente existe un establecimiento de este tipo, localizado en Bergen. Estas tiendas constituyen la única vía de acceso del público a algo parecido al vino fuera del monopolio, pero la ínfima calidad de esta bebida limita su clientela a los grupos sociales de menor poder adquisitivo. 
tes pidan una marca concreta y se contenten con otra de la misma zona a sugerencia del vendedor, por motivos de precio o por agotamiento puntual de la referencia solicitada. De momento, y por ese orden, precio/calidad, destino, territorio y marca se perfilan como los cuatro factores fundamentales en la conformación de las pautas de adquisición de vinos. Elementos como el tipo de uva, la añada o la forma de elaboración son manejadas solamente por los expertos e ignoradas por la inmensa mayoría de los consumidores.

En definitiva, el cliente noruego comienza a mirar al vino con otros ojos: lo consume en mayor cuantía, con más frecuencia y con cierto criterio, sin preocuparse tanto por el precio a cambio de un producto mejor, una vez que empieza a diferenciar las calidades como consecuencia de sus viajes al extranjero y de la posibilidad de adquirir buenos vinos a precios relativamente prudentes tras la liberalización de las importaciones. La integración cultural y económica de Noruega en el entorno comunitario trae consigo, por tanto, el declive del consumo de bebidas fuertes y su progresiva sustitución por un producto no local que, además, modifica sutilmente la relación de los ciudadanos con las bebidas alcohólicas, más integradas en la vida cotidiana.

\section{La presencia de los vinos españoles en Noruega}

Una aproximación inicial a partir de las cifras de ventas del Vinmonopolet (cuadro 1) da buena cuenta de la contrastada trayectoria reciente del vino español en Noruega. En conjunto, entre 1994 y 2002 ha ganado 4 puntos porcentuales, desde el 11,2\% al 15,1\% de las ventas en litros, manteniéndose como tercer abastecedor por detrás de Francia $(30,1 \%)$ e Italia (18,2\%), quedando Alemania y Bulgaria como grandes perjudicados de este período. En índices 1994=100, España llega a 2002 con un valor de 226, sólo superado, entre los países relevantes, por Italia (682), y muy por delante de Chile (207) y Francia (177). Los tres primeros proveedores han pasado de acumular el 58,2\% del mercado local en 1994 (Francia, Alemania y España) al 63,4\% en 2002 (Francia, Italia y España), por lo que el proceso de liberalización parece apuntar en la línea habitual de consolidación de los productores más tradicionales y asentados.

Pese a este favorable balance global, hay que diferenciar con nitidez dos etapas. Al final de la primera (1994-1998), España alcanza su cuota máxima (18,7\%), colocándose en segundo lugar por detrás de Chile $(19,6 \%)$ y por delante de Francia $(17,1 \%)$, Alemania $(10,4 \%)$ y, sobre todo, Italia (con una modesta penetración del 6,4\%); en este momento, los tres primeros suministradores sumaban sólo el 55,4\% del mercado, por lo que el nuevo marco competitivo se tradujo en cierto reequilibrio, con Chile y España como principales beneficiados. Desde entonces (1999-2002), Francia e Italia avanzan con enorme rapidez en detrimento de las posiciones chilenas, españolas y alemanas, hasta completar el mapa actual, con la espectacular irrupción de los caldos transalpinos como principal novedad.

Las mutaciones de la demanda justifican estas transformaciones en la distribución geográfica de las cuotas de mercado. El tímido crecimiento del vino blanco (19\%) explica el retroceso alemán, que solamente vende en Noruega caldos de este tipo; todavía conserva el 35\% de este segmento, por delante de Francia (32\%), que ha recortado mucho la ventaja inicial de su rival (55\% frente a $17 \%$ en 1998$)$.

El mercado de los vinos espumosos, patrimonio español hasta 1998 (60\%, frente al $23 \%$ de Francia) por su excelente relación calidad-precio, presenta ahora una distribución más equilibrada debido a la rápida penetración italiana, que disfruta hoy de un $32 \%$ de este segmento, frente al parco 36\% correspondiente a España. No obstante, el consumo de estos vinos apenas crece (10\%), alternando años de mejoría con otros de retroceso una vez 
Cuadro 1: Ventas de vino en Noruega por clases y por país de origen (1994-2002)

\begin{tabular}{|c|c|c|c|c|c|c|c|c|c|}
\hline Vino Tinto & 1994 & 1995 & 1996 & 1997 & 1998 & 1999 & 2000 & 2001 & 2002 \\
\hline Francia & 5.609 & 4.538 & 3.686 & 3.601 & 3.962 & 5.061 & 7.162 & 8.486 & 9.665 \\
\hline España & 1.940 & 2.738 & 2.989 & 3.865 & 5.181 & 5.175 & 4.780 & 5.016 & 5.769 \\
\hline Chile & 2.205 & 2.342 & 2.546 & 4.759 & 6.210 & 7.318 & 6.346 & 5.765 & 4.807 \\
\hline Bulgaria & 1.399 & 2.331 & 3.040 & 2.985 & 1.784 & 1.227 & 668 & 387 & 263 \\
\hline Italia & 904 & 1.287 & 1.385 & 1.552 & 1.736 & 2.401 & 5.931 & 6.050 & 6.824 \\
\hline Australia & 951 & 1.147 & 1.502 & 1.439 & 1.547 & 1.874 & 1.825 & 1.669 & 1.611 \\
\hline Portugal & 369 & 663 & 809 & 882 & 1.072 & 1.087 & 984 & 1.065 & 1.199 \\
\hline Sudáfrica & 505 & 468 & 570 & 366 & 353 & 490 & 669 & 845 & 747 \\
\hline Argentina & 267 & 302 & 259 & 259 & 235 & 176 & 192 & 221 & 177 \\
\hline EEUU & 228 & 298 & 310 & 415 & 445 & 596 & 592 & 668 & 684 \\
\hline Hungría & 261 & 217 & 209 & 211 & 191 & 145 & 165 & 205 & 211 \\
\hline Otros Países & 1.796 & 1.772 & 1.753 & 1.633 & 1.437 & 1.210 & 992 & 774 & 503 \\
\hline Subtotal Vino Tinto & 16.434 & 18.103 & 19.058 & 21.967 & 24.153 & 26.760 & 30.306 & 31.151 & 32.460 \\
\hline Vino Blanco & 1994 & 1995 & 1996 & 1997 & 1998 & 1999 & 2000 & 2001 & 2002 \\
\hline Alemania & 4.774 & 4.476 & 4.047 & 3.972 & 3.497 & 3.546 & 3.458 & 3.495 & 3.645 \\
\hline Francia & 1.524 & 1.356 & 1.018 & 1.123 & 1.508 & 2.089 & 2.612 & 2.828 & 3.314 \\
\hline Australia & 430 & 538 & 663 & 681 & 609 & 602 & 560 & 529 & 509 \\
\hline España & 400 & 445 & 461 & 554 & 575 & 539 & 498 & 497 & 496 \\
\hline Chile & 244 & 350 & 383 & 478 & 374 & 415 & 346 & 270 & 260 \\
\hline Italia & 273 & 307 & 322 & 300 & 404 & 370 & 390 & 727 & 838 \\
\hline Portugal & 146 & 147 & 155 & 159 & 134 & 116 & 102 & 96 & 138 \\
\hline Hungría & 148 & 125 & 122 & 293 & 406 & 379 & 384 & 445 & 688 \\
\hline EEUU & 119 & 125 & 138 & 186 & 191 & 170 & 149 & 119 & 114 \\
\hline Eslovenia & 152 & 115 & 89 & 58 & 29 & 22 & - & - & - \\
\hline Sudáfrica & - & - & 120 & 104 & 96 & 119 & 105 & 93 & 80 \\
\hline Otros Países & 458 & 659 & 483 & 681 & 548 & 476 & 399 & 303 & 272 \\
\hline Subtotal Vino Blanco & 8.668 & 8.643 & 8.001 & 8.589 & 8.371 & 8.843 & 9.003 & 9.402 & 10.354 \\
\hline Vino Rosado & 1994 & 1995 & 1996 & 1997 & 1998 & 1999 & 2000 & 2001 & 2002 \\
\hline Portugal & 167 & 169 & 158 & 148 & 120 & 121 & 101 & 88 & 84 \\
\hline Francia & 124 & 88 & 78 & 75 & 64 & 69 & 58 & 62 & 68 \\
\hline Otros Países & 13 & 16 & 17 & 18 & 18 & 24 & 27 & 38 & 53 \\
\hline Subtotal Vino Rosado & 304 & 273 & 253 & 241 & 202 & 214 & 186 & 188 & 205 \\
\hline Vino Espumoso & 1994 & 1995 & 1996 & 1997 & 1998 & 1999 & 2000 & 2001 & 2002 \\
\hline España & 620 & 655 & 578 & 546 & 513 & 576 & 446 & 429 & 418 \\
\hline Francia & 241 & 213 & 197 & 205 & 203 & 299 & 218 & 223 & 238 \\
\hline Italia & - & - & - & - & - & - & 345 & 342 & 364 \\
\hline Otros países & 178 & 111 & 126 & 130 & 154 & 410 & 81 & 83 & 118 \\
\hline Subtotal Espumoso & 1.039 & 979 & 901 & 881 & 870 & 1.285 & 1.090 & 1.077 & 1.138 \\
\hline Otros vinos & 1.610 & 1.519 & 1.446 & 1.390 & 1.328 & 1.370 & 1.359 & 1.373 & 1.529 \\
\hline Total & 28.055 & 29.517 & 29.659 & 33.068 & 34.924 & 38.472 & 41.944 & 43.191 & 45.686 \\
\hline
\end{tabular}

Fuente: Informes anuales del Vinmonopolet. Elaboración propia.

Nota: datos en miles de litros.

perdida su tradicional imagen de excepcionalidad en favor de los tintos de calidad, lo que reclama un esfuerzo por parte de los elaboradores para dotar al espumoso de un espacio propio dentro la cultura vinícola noruega.

Es en el mercado de tintos donde los cambios han sido más notorios, hasta el punto de condicionar la trayectoria del conjunto debido a un significativo incremento del $98 \%$ de volumen vendido a lo largo de los ocho años considerados, que explica a su vez la cifra de crecimiento medio del mercado (63\%). También en este segmento los vinos italianos han 
experimentado un crecimiento fulgurante (del 5,5\% de 1994 al 21\% de 2002), seguidos a cierta distancia por los españoles (del 11,8\% al 17,8\%), mientras Francia cede posiciones (del $34,1 \%$ al 29,8\%), Chile se mantiene $(13,4 \%$ y 14,8\%) y Bulgaria prácticamente desaparece (del 8,5\% al 0,8\%). Pero la mera comparación del primer y el último año de la serie oculta los interesantes movimientos intermedios, lo que de nuevo exige diferenciar los períodos 1994-1998 y 1999-2002.

En un primer momento, son Chile y España los países que aprovechan la liberalización, hasta el punto de que en 1998 el consumo de vino francés decaía un 29\% respecto a 1994, pero el de vinos chilenos y españoles se multiplica por 2,8 y 2,6, respectivamente. Para explicar estas tendencias, los expertos entrevistados aluden a causas políticas (boicot a los productos galos como manifestación de rechazo por las pruebas nucleares de Mururoa), técnicas (uso adecuado del roble en los vinos españoles de crianza, que proporciona un gusto apreciado por el consumidor noruego) y de precio (chilenos y españoles dominan el formato bag-in-box) que pusieron en apuros a los caldos franceses, asociados a una imagen de exclusividad y altos precios, mientras a los españoles se les atribuía una calidad levemente inferior, aunque sus ajustados precios ayudan a conformar un artículo más equilibrado desde la perspectiva comercial.

Sin embargo, este prometedor arranque en el segmento más comprometido y lucrativo se ha visto truncado por la meritoria recuperación francesa y la sensacional progresión italiana, que multiplican sus ventas por 2,4 y 3,9, respectivamente, entre 1998 y 2002 . Ello hace descender las ventas de Chile y apenas deja crecer a las españolas, lo que se traduce en pérdidas de once y cuatro puntos porcentuales, respectivamente.

Conviene preguntarse, pues, por las causas de tan drástico cambio en las fuentes de abastecimiento del mercado vinícola noruego. A juicio de los agentes locales, la imagen de marca colectiva proporcionada por las Denominaciones de Origen españolas (Rioja y Penedés, principalmente, seguidas a gran distancia por Navarra, Ribera del Duero o Rías Bajas) ha constituido un poderoso reclamo comercial ante el comedido y exigente consumidor noruego, celoso de la garantía de recibir calidad a cambio de su dinero. Combinados estos vinos con el bag-in-box procedente de regiones de amplia producción como La Mancha, Jumilla, Utiel-Requena, Tierra de Barros, el Bierzo o el propio Penedés, España atiende los dos tipos principales de consumo en Noruega: el más frecuente de vinos dignos y baratos, en competencia con los productores chilenos, y el más meditado de vinos de calidad a precios razonables, donde rivaliza con los demás países mediterráneos europeos.

Sin embargo, el avance inicial de España se explica más por el tirón de la demanda noruega que como resultado de su propio interés por consolidarse en este país. Los intermediarios locales compensan la escueta labor promocional que desarrollan en Noruega los agentes individuales y colectivos del sector vinícola español enviando a sus propios catadores y agentes a las comarcas consolidadas o emergentes (Toro, Rueda, Priorato). Esta desidia comercial se manifiesta en el predominio de las referencias geográficas más tradicionales de España y en la lentitud con que se difunden las nuevas Denominaciones de Origen y sus peligrosas consecuencias comienzan a dejarse sentir una vez que los distintos competidores redefinen sus posiciones tras la liberalización.

En efecto, los importadores noruegos dan cuenta de numerosas misiones comerciales organizadas por asociaciones de productores italianos y franceses, que parecen encontrar reflejo directo e inmediato en las cifras absolutas de ventas y en la consiguiente distribución geográfica de la cuota de mercado, una vez ajustados los precios de los vinos franceses del segmento medio y puesta en marcha la proverbial competencia comercial italiana. El Vinmonopolet se jacta en sus informes de no dejarse tentar por el favoritismo 
(hacia países o marcas concretas) y de tomar sus decisiones de compra ajustándose a criterios de precio, calidad y adecuación a la demanda ${ }^{5}$. En este sentido, Italia y Francia parecen haber reaccionado con lentitud, pero con firmeza, ante las nuevas posibilidades de competencia por el suministro al Vinmonopolet y vienen desplegando desde hace algunos años campañas promocionales genéricas, asociando la calidad a los vinos del conjunto del país y no a sus D.O. de forma individual, a fin de evitar la saturación de información que para el consumidor supone la proliferación de indicaciones geográficas remotas.

España, pues, parece encontrar dificultades para definir con precisión su nicho de mercado en Noruega, entre el bag-in-box (encarnado por el declinante Chile) y el château (emblema de la Francia clásica). Ello le ha permitido mantener posiciones, pero le ha impedido crecer como los rivales con mejor imagen de calidad (Francia) y una mentalidad comercial más agresiva (Italia). La misma evolución reciente del mercado noruego parece apuntar hacia un consumo de más nivel, avalado por el modelo europeo de producción vinícola regulada y ligada a un marco geográfico específico. Los países de la Europa meridional (Francia, Italia, España y Portugal) sumaban el 46\% de las ventas en 1994, pero llegaban al máximo del 66,6\% en 2002, tras alcanzar en 1997 un mínimo del 41\%; mientras tanto los nuevos productores (EEUU, Argentina, Chile, Australia y Sudáfrica) sólo pasaban del 18,7\% al 20,4\%, por debajo del máximo del 30\% alcanzado en 1998 . Esto, que puede interpretarse como un típico efecto de redistribución de los flujos comerciales relacionado con el ingreso en el Espacio Económico Europeo (Lobejón, 2001), responde también a la lenta aproximación del consumo vinícola noruego al patrón mediterráneo de mayor asiduidad y creciente interés por la calidad, en una manifestación más de la recurrente preocupación de los consumidores europeos por la trazabilidad de sus alimentos (Murdoch, Marsden y Banks, 2000).

\section{Conclusiones: el modelo noruego ante el debate entre liberalización e intervención}

Los cambios suscitados en el mercado noruego del vino desde 1996 permiten hablar de transición controlada desde el modelo de gobernación centralizada hacia un nuevo esquema más plural en su vertiente económica, pero subordinado a los imperativos de servicio público eficaz y preservación de la salud que animan la labor del Vinmonopolet.

La liberalización de las importaciones ha traído mayor eficiencia al mercado HORECA, que opera fuera de los cauces estatales y se ha convertido en principal vía de introducción de nuevas marcas. También ha propiciado una contención de los precios muy favorable para el acceso de nuevas capas del público a vinos de mayor calidad. Los nuevos gustos colectivos impulsan así mismo esta nueva forma de beber vino que comienza a extenderse en Noruega y que se plasma en la demanda de los bag-in-box para uso más habitual y en la paralela caída del consumo de bebidas de mayor graduación. En consecuencia, parece que tras la apertura comercial surgen indicios de una pautas de consumo más cercanas al modelo mediterráneo que al septentrional, aunque hablar de convergencia cultural resulta todavía prematuro.

No en vano, las barreras al consumo cotidiano son aún muy fuertes debido al formato de las tiendas del Vinmonopolet, expresión de arraigadas convenciones sociales. El futuro de esta institución parece asegurado puesto que los litigios jurídicos interpuestos en Suecia contra el monopolio estatal (Systembolaget) han sido resueltos por las instituciones comu-

5 Hasta el punto de que los mayoristas, importadores y distribuidores pueden recurrir las ofertas rechazadas por el Vinmonopolet ante un comité ministerial. 
nitarias a favor del statu quo actual. La presión de los grupos religiosos y la satisfacción de la clientela con los servicios recibidos en sus tiendas son argumentos, quizá más poderosos, a favor de su continuidad. Debe reconocerse que se trata de establecimientos de gran calidad atendidos por personal muy cualificado, cuya oferta supera de largo a la del comercio especializado de países como España o Francia donde, salvo en determinados establecimientos ubicados en las principales ciudades, el número de referencias disponibles es muy inferior. La gestión centralizada de la oferta como un servicio público ha facilitado el desarrollo de una eficaz red comercial que proporciona al cliente amplias posibilidades de elección a partir de la información objetiva de los catálogos. De forma paradójica, la intervención rigurosa deviene en un mecanismo neutral y transparente de transmisión de la información, imprescindible para el buen funcionamiento de cualquier mercado.

En este mundo sin publicidad, la calidad y el precio son esenciales para ganar cuota de mercado. Los vinos españoles pueden competir en ambos campos y las consecuencias beneficiosas de la apertura del mercado noruego no se han hecho esperar en este sector industrial maduro ni para los sistemas productivos locales especializados en vinos protegidos ni para quienes persisten en su dedicación a los graneles, poco apreciados en España pero con buena salida en Escandinavia. Sin embargo, la posición española se debe más al interés de los agentes noruegos por adquirir vinos que interesan a los clientes que a la labor comercial de las bodegas españolas.

En definitiva, el análisis de las tendencias del mercado del vino en Noruega después de su ingreso en el Espacio Económico Europeo refleja que la integración comercial tiene efectos significativos de carácter local y global que pueden ser controlados con una acción pública consciente y flexible, propia de ese Estado cualitativo (O'Neill, 1997) que se implica en la gestión económica con objetivos definidos, presididos por la prioridad del interés común. En la esfera global destaca la redefinición del mapa de las importaciones, con la consiguiente exigencia de nuevas estrategias comerciales en los países productores. En la escala local se asiste a una modificación de los hábitos de consumo (pautas temporales, productos preferidos) donde los elementos exógenos se entremezclan con la idiosincrasia nacional para dar lugar a una síntesis armónica entre nuevos y viejos valores. La gestión de estos cambios en Noruega no se ha dejado a merced del libre mercado, sino que la regulación de la demanda continúa en manos del Estado, que ha liberalizado los campos susceptibles de ganar eficiencia conservando a cambio el control del acceso de los ciudadanos al vino. Se consigue así mejorar la oferta en cantidad y calidad sin que de ello se derive un crecimiento indiscriminado del consumo que la sociedad noruega ha entendido y entiende como indeseable para la colectividad.

\section{Bibliografía}

ALONSO SANTOS, J.L. y MÉNDEZ GUTIÉRREZ DEL VALLE, R. (coords.) (2000): Innovación, pequeña empresa y desarrollo local en España. Civitas. Madrid, 323 pp.

AMIN, S. (1999): El capitalismo en la era de la globalización. Paidós Estado y Sociedad. Barcelona, 188 pp.

ANTONELLI, C. y FERRÃO, J. (coords.) (2001): Comunicação, conhecimento colectivo e inovação. As vantagens da aglomeração geográfica. Instituto de Ciências Sociais. Colecção Estudos e Investigações $\mathrm{n}^{\circ} 17$. Lisboa, $231 \mathrm{pp}$.

BATHELT, H. y GLÜCKLER, J. (2003): «Toward a Relational Economic Geography». Journal of Economic Geography vol. 3, pp. 117-144.

BUESA, M. y MOLERO, J. (1998): Estructura industrial de España. Organización, tecnología e internacionalización. Civitas. Madrid, 284 pp. 
CORBIN, A. y PERROT, M. (1993): «Entre bastidores». En Ariès, Ph. y Duby, G. (dirs.): Historia de la Vida Privada. Volumen IV: De la Revolución Francesa a la Primera Guerra Mundial. Círculo de Lectores. Barcelona, pp. 419-620.

DICKEN, P. (2003): Global shift. Reshaping the Global Economic Map in the 21st Century. Sage. Londres ( $4^{\mathrm{a}}$ edición), $632 \mathrm{pp}$.

DUPUY, Cl. y BURMEISTER, A. (dirs.) (2003): Entreprises et territoires. Les nouveaux enjeux de la proximité. Notes et Études Documentaires n 5167. La Documentation Française. París, 134 pp.

GILLY, J.P. y TORRE, A. (dirs.) (2001): Dynamiques de proximité. L'Harmattan. París, 301 pp.

KRUGMAN, P. (1997): Desarrollo, geografía y teoría económica. Antoni Bosch. Barcelona, 113 pp.

LE GARS, C. y HINNEWINKEL, J.C. (2000): «Le commerce mondial des vins a la fin du XX siécle». Annales de Géographie no 614-615, pp. 381-394.

LOBEJÓN HERRERO, L.F. (2001): El comercio internacional. Akal. Tres Cantos (Madrid). 164 pp.

MALMBERG, A. (1996): «Industrial Geography: Agglomeration and Local Milieu». Progress in Human Geography vol. 20, pp. 392-403.

MARKUSEN, A. (1996): «Sticky Places in Slippery Space: a Typology of Industrial Districts». Economic Geography vol. 72, pp. 293-313.

MASKELL, P. y otros (1998): Competitiveness, Localised Learning and Regional Development. Specialisation and Prosperity in Small Open Economies. Routledge. Londres, 256 pp.

MARTÍNEZ GONZÁLEZ-TABLAS, A. (2000): Economía política de la globalización. Ariel. Barcelona, $380 \mathrm{pp}$.

MÉNDEZ GUTIÉRREZ DEL VALLE, R. (1997): Geografía económica. La lógica espacial del capitalismo global. Ariel. Barcelona, 384 pp.

MURDOCH, J.; MARSDEN, T. y BANKS, J. (2000): «Quality, Nature and Embeddedness: some Theoretical Considerations in the Context of the Food Sector». Economic Geography vol. 76, pp. 107-125.

O’NEILL, P.M. (1997): «Bringing the Qualitative State into Economic Geography». En Lee, R. y Wills, J. (eds): Geographies of Economies. Arnold. Londres, pp. 290-301.

ORFALI, K. (1993): «Un modelo de transparencia: la sociedad sueca». En Ariès, Ph. y Duby, G. (dirs.): Historia de la Vida Privada. Vol. V: De la Primera Guerra Mundial a nuestros días. Círculo de Lectores. Barcelona, pp. 581-613.

PALAZUELOS, E. y VARA. Ma J. (coords.) (2002): Grandes áreas de la economía mundial. Ariel. Barcelona, $345 \mathrm{pp}$.

PORTER, M. (1991): La ventaja competitiva de las naciones. Plaza y Janés Editores. Barcelona, $1.026 \mathrm{pp}$.

SALOM CARRASCO, J. (2003): «Innovación y actores locales en los nuevos espacios económicos: un estado de la cuestión». Boletín de la Asociación de Geógrafos Españoles n 36, pp. 7-30.

SÁNCHEZ, HERNÁNDEZ, J.L. (2003): Naturaleza, localización y sociedad. Tres enfoques para la Geografía Económica. Ediciones Universidad de Salamanca. Salamanca, 257 pp.

VINMONOPOLET: Årsberetning og regnskap [Informe Anual y Balance]. Oslo. Vinmonopolet A/ S. Años 1998, 1999, 2000, 2001 y 2002. 